\title{
THE KINETICS OF BICARBONATE REABSORPTION DURING ACUTE RESPIRATORY ACIDOSIS*
}

\author{
By WILLIAM B. SCHWARTZ, $\dagger$ ADRIEN FALBRIARD $\ddagger$ AND GUY LEMIEUX§ \\ (From the Medical Service, New England Center Hospital, and the Department of Medicine, \\ Tufts University School of Medicine, Boston, Mass.)
}

(Submitted for publication December 24, 1958; accepted January 22, 1959)

It is well-known that acute elevation of blood $\mathrm{pCO}_{2}$ is accompanied by a rise in the renal reabsorption of bicarbonate (1-3). The exact mechanism through which this occurs has not been established, but it is thought to result from accelerated tubular hydrogen secretion due either to the lowering of cellular $\mathrm{pH}$ or to an increased formation of carbonic acid.

The present experiments were undertaken in an attempt to define further the nature of the reabsorptive process during acute respiratory acidosis. The data demonstrate that during an acute sustained increase of carbon dioxide tension, progressive elevation of plasma bicarbonate concentration was accompanied by a curvilinear increase in the rate of bicarbonate reabsorption. The relationship between plasma bicarbonate concentration and the rate of reabsorption was found, by means of the double reciprocal plot, to take the form $y=\frac{a x}{b+x}$. The possible significance of this finding has been considered.

\section{MATERIALS AND METHODS}

Twelve experiments were performed on female mongrel dogs anesthetized with sodium pentobarbital. An endotracheal tube fitted with an inflatable balloon was introduced into the trachea and connected either to a calibrated volume displacement ventilator (Etsten Ventilator) (4) or to a Mine Safety "Pneophore." Respiratory movements were inhibited by the administration of gallamine triethiodide (Flaxedil ${ }^{\circledR}$ ) so that respiratory exchange could be controlled by the ventilator. Blood $\mathrm{pCO}_{2}$ was increased to values of approximately 90 to $100 \mathrm{~mm} . \mathrm{Hg}$ by having the animal breathe a mixture of 9 per cent $\mathrm{CO}_{2}$ and 91 per cent oxygen. This tension was then kept as constant

* Supported in part by grants from the National Heart Institute, National Institutes of Health, United States Public Health Service, and the American Heart Association.

$\dagger$ Established Investigator of the American Heart Association.

$\ddagger$ Lederle Traveling Fellow.

\&edical Research Fellow, National Research Council, Canada. as possible. When elevated blood $\mathrm{pCO}_{2}$ had been steadily maintained for at least one hour and adequate urine flow ( 3.6 to $6.2 \mathrm{ml}$. per minute) had been achieved by constant infusion of isotonic mannitol, plasma bicarbonate concentration was progressively increased by intravenous infusion of 0.142 to 0.285 molar solution of sodium bicarbonate at a rate of $7 \mathrm{ml}$. per minute. In the majority of the experiments, it was necessary to increase ventilation slightly in order to prevent the rise in $\mathrm{CO}_{2}$ tension which usually followed the rapid infusion of bicarbonate.

The clearance of exogenous creatinine was used as a measure of glomerular filtration rate. Urine was collected under mineral oil through an inlying catheter and the bladder was emptied by manual compression at the beginning and at the end of each 10 minute collection period. Heparinized blood samples were drawn anaerobically from the femoral artery. Plasma and urine were analyzed for creatinine by a modification of the method of Bonsnes and Taussky (5) and for total $\mathrm{CO}_{2}$ by the manometric method of Van Slyke. Blood and urine $\mathrm{pH}$ were measured anaerobically at $37^{\circ} \mathrm{C}$. using a Cambridge Research Model $\mathrm{pH}$ meter. Concentration of bicarbonate and dissolved $\mathrm{CO}_{2}$ were calculated from the Henderson-Hasselbalch equation, using a $\mathrm{pK}^{\prime}$ for carbonic acid of 6.1 and $0.0591 \alpha$ equal to 0.0301 for plasma and 0.0309 for urine. Filtered bicarbonate was taken as the product of the filtration rate and the plasma bicarbonate concentration (corrected for a Donnan factor of 1.05). Potassium in serum was determined with an internal standard flame photometer.

Seven control experiments were performed with the animals breathing 100 per cent oxygen and with the $\mathrm{pCO}_{2}$ maintained at normal levels by controlled ventilation with the Etsten Ventilator. Plasma bicarbonate concentration was increased by intravenous infusion of 0.142 to 0.595 molar solution of sodium bicarbonate at a rate of $7 \mathrm{ml}$. per minute. The higher concentrations of bicarbonate used in the control studies were necessary in order to achieve plasma bicarbonate concentrations comparable to those attained in the high $\mathrm{pCO}_{2}$ experiments.

\section{RESULTS}

Table I shows the data from a typical experiment in which plasma bicarbonate level was raised progressively during acute, sustained respiratory acidosis. Initially, when plasma bicarbonate was $23.5 \mathrm{mEq}$. per L., there was only slight excretion of bicarbonate and thus nearly complete reabsorption. As the plasma level was 
TABLE I

Effect of acute sustained respiratory acidosis on bicarbonate reabsorption during progressive elevation of plasma bicarbonate levels*

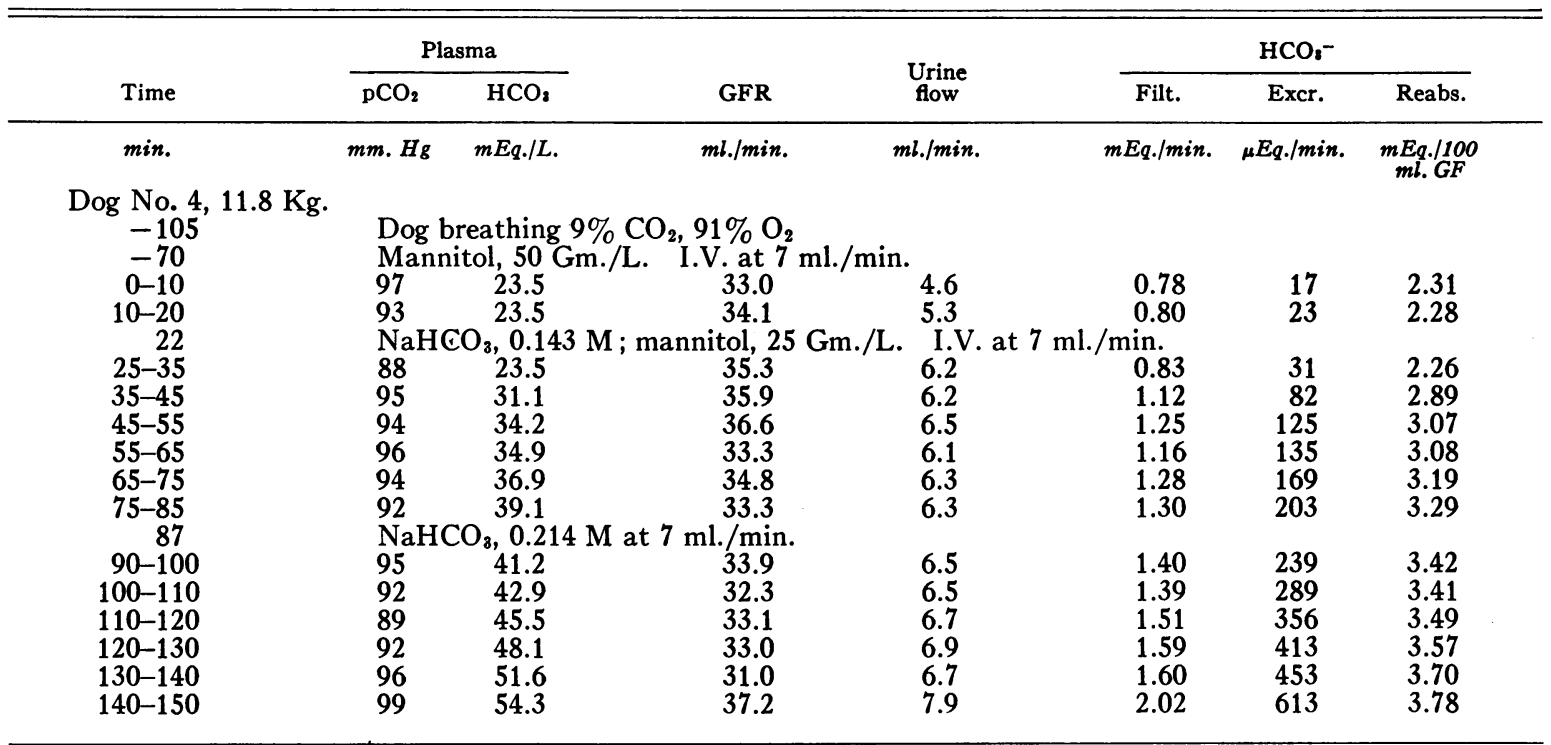

* Plasma bicarbonate values have been corrected for a Donnan factor of 1.05 .

elevated, there was a prompt and progressive increase in both the excretion and reabsorption of bicarbonate. The reabsorptive rate observed at $54.3 \mathrm{mEq}$. per L., the highest plasma level studied, was $3.78 \mathrm{mEq}$. per $100 \mathrm{ml}$. of glomerular filtrate. Plasma carbon dioxide tension ranged between 88 and $99 \mathrm{~mm}$. $\mathrm{Hg}$ during the course of the study.

Table II shows the results of another representative experiment. The data again demon- strate a progressive increase in both the excretion and reabsorption of bicarbonate as the plasma bicarbonate concentration was elevated from 28.8 to a final value of $55.8 \mathrm{mEq}$. per $\mathrm{L}$. The final reabsorption was $4.29 \mathrm{mEq}$. per $100 \mathrm{ml}$. of glomerular filtrate. As in the experiment shown in Table $\mathrm{I}, \mathrm{pCO}_{2}$ and glomerular filtration were nearly constant during the course of the study.

The results of all 12 experiments are shown in Figure 1. On the abscissa is plasma (filtrate)

TABLE II

Effect of acute sustained respiratory acidosis on bicarbonate reabsorption during progressive elevation of plasma bicarbonate levels*

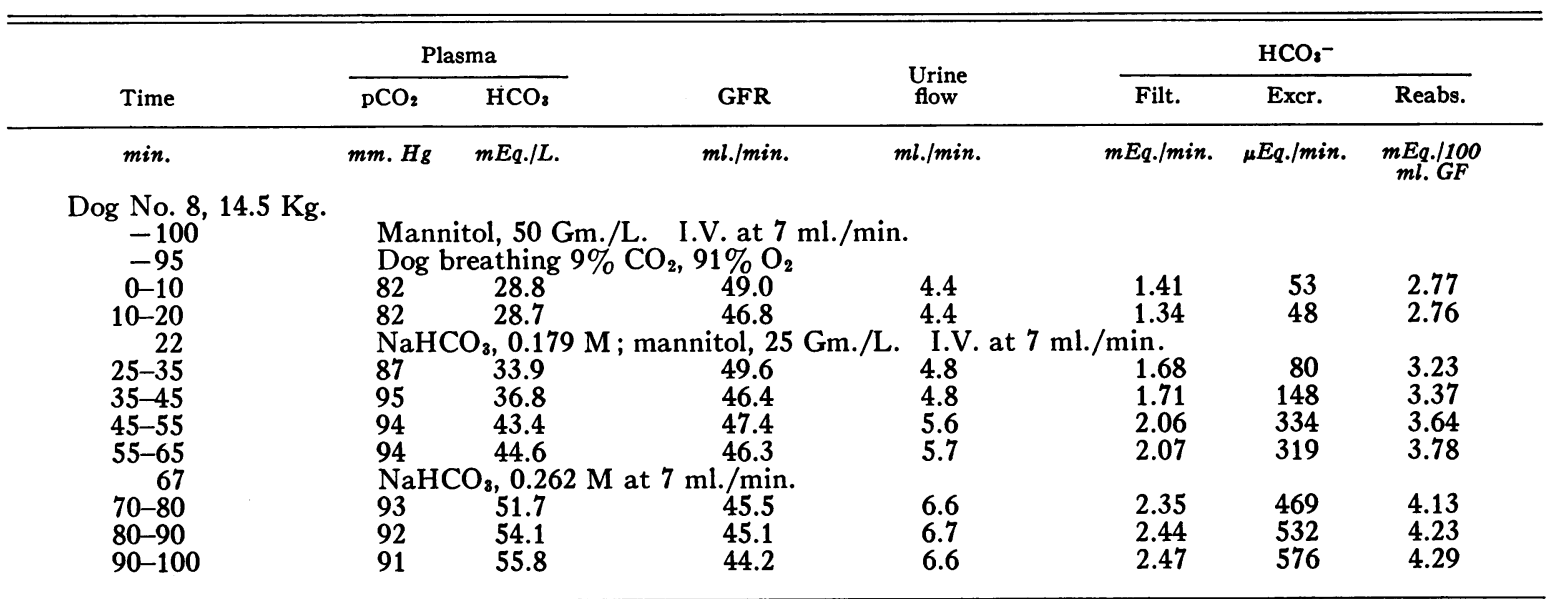

* Plasma bicarbonate values have been corrected for a Donnan factor of 1.05. 


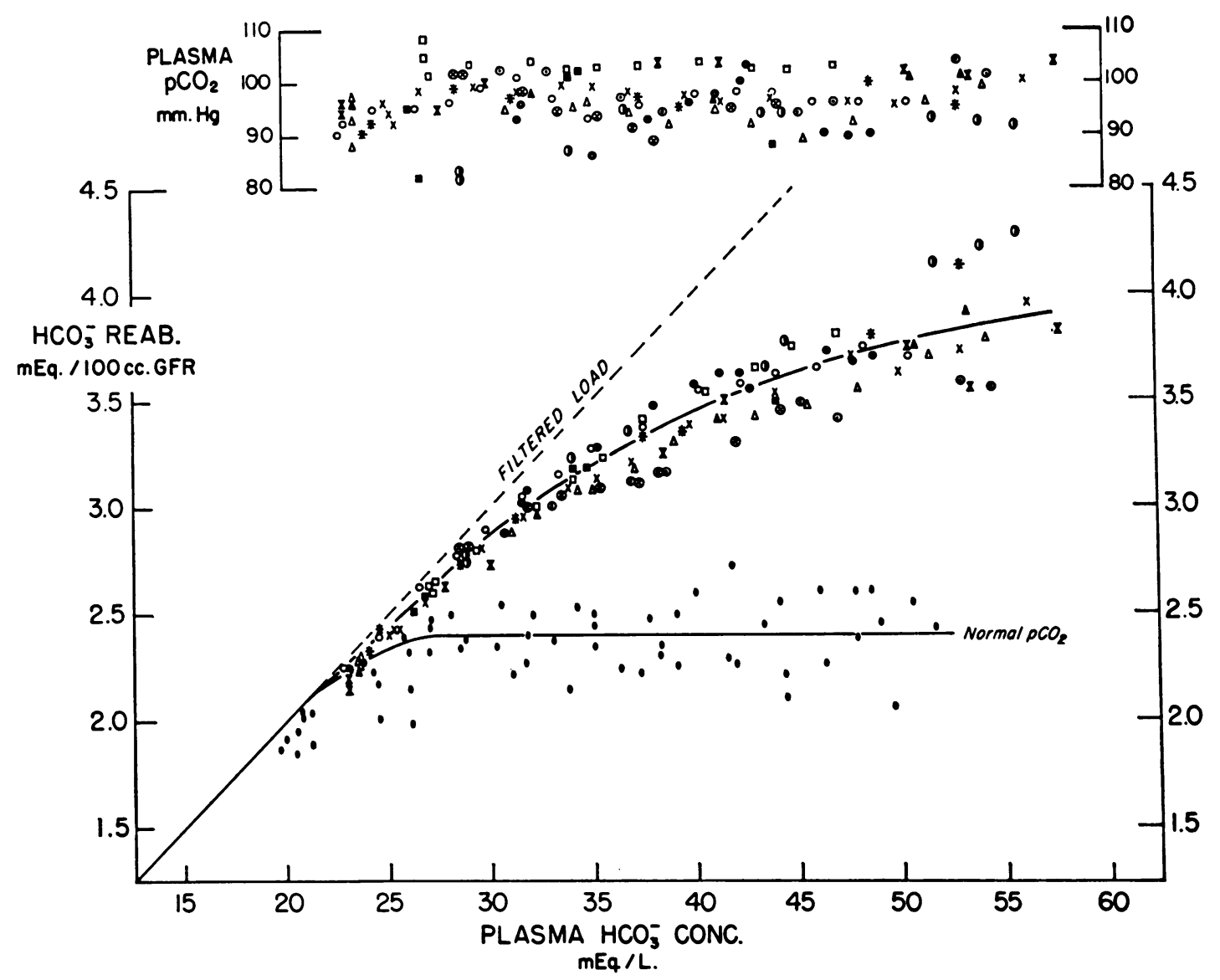

Fig. 1. Effect of Acute Sustained Respiratory Acidosis on Bicarbonate Reabsorption During Progressive Elevation of Plasma Bicarbonate Concentration (12 Experiments)

The curved line has been drawn through the experimental points by inspection. Data from the seven control experiments, carried out at normal $\mathrm{pCO}_{2}$ values, are shown in the lower half of the chart. Values for $\mathrm{pCO}_{2}$ of this group (not shown) ranged between 35 and $45 \mathrm{~mm}$. of $\mathrm{Hg}$.

bicarbonate level (mEq. per L.) and on the ordinate is bicarbonate reabsorption (mEq. per 100 ml. of glomerular filtrate). The straight line bisecting the chart indicates the filtered load of bicarbonate. The curved line was drawn through the experimental points by inspection. It can be seen that with elevation of the plasma bicarbonate level from 24 to $55 \mathrm{mEq}$. per L. there was a curvilinear rise in bicarbonate reabsorption, which, at the highest plasma concentration studied, reached a mean value of approximately $3.8 \mathrm{mEq}$. per $100 \mathrm{ml}$. of glomerular filtrate. Frank excretion of bicarbonate began at a plasma level of 26 to $30 \mathrm{mEq}$. per L. The observed values for plasma $\mathrm{pCO}_{2}$ shown in the upper part of Figure 1 ranged from 82 to $108 \mathrm{~mm}$. $\mathrm{Hg}$. In eight of the 12 experiments, however, the $\mathrm{pCO}_{2}$ remained within a range of $10 \mathrm{~mm} . \mathrm{Hg}$ and in the group as a whole $\mathrm{pCO}_{2}$ showed no significant trend during the course of the study. Variations in glomerular filtration rate during the course of the experiments were usually small and in no instance differed from the control values by more than 20 per cent.

In contrast, during the seven control experiments (Figure 1), bicarbonate reabsorption remained at approximately $2.4 \mathrm{mEq}$. per $100 \mathrm{ml}$. of glomerular filtrate for the group as a whole when plasma bicarbonate concentration was progressively elevated from normal levels to more than $50 \mathrm{mEq}$. per $\mathrm{L}$. The range of reabsorptive values was 2.2 to $2.7 \mathrm{mEq}$. per $100 \mathrm{ml}$. of glomerular filtrate. $\mathrm{pCO}_{2}$ remained between 35 and $45 \mathrm{~mm} . \mathrm{Hg}$ throughout the study; these values are not shown in Figure 1.

Serum potassium concentration fell in both the 


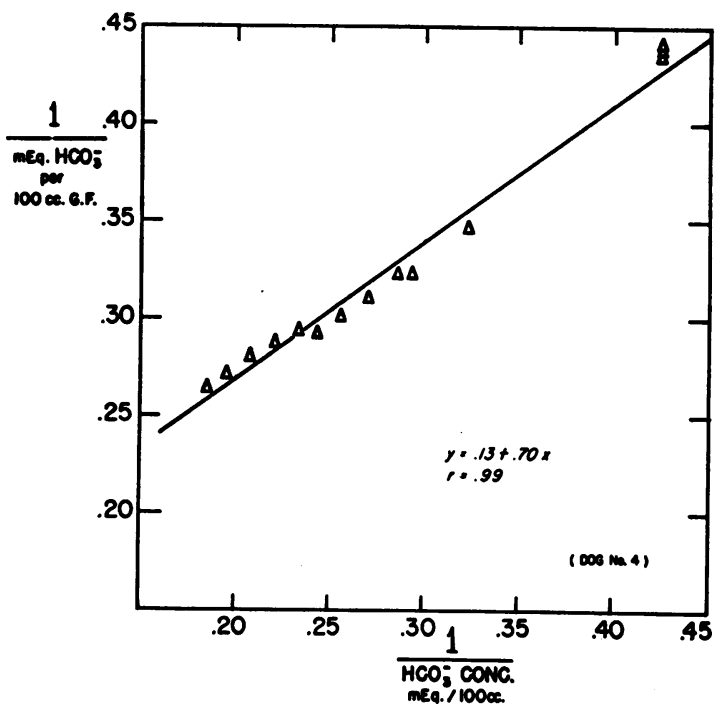

Fig. 2. Double Reciprocal Plot of Data FROM TABLE I

The line through the points was calculated by the method of least squares.

control and the respiratory acidosis studies. The final mean value in the control group was 2.1 mEq. per L. (range, 1.7 to 2.4). S.E. $\bar{x}$ equaled 0.12 . In the acidosis group the value was 2.3 mEq. per L. (range, 1.7 to 2.9 ). S.E. $\bar{x}$ equaled 0.13. The difference between the means was not significant $(p>0.2)$.

\section{DISCUSSION}

It has previously been shown that acute elevation of plasma bicarbonate concentration increases the renal reabsorption of bicarbonate (1-3). The present data demonstrate that the reabsorptive rate is a function of the plasma bicarbonate level, and that elevation of $\mathrm{pCO}_{2}$ does not simply increase the reabsorptive capacity to a single new constant rate. Frank bicarbonate excretion began at a plasma level of approximately 26 to $30 \mathrm{mEq}$. per L., and there was a progressive increase in both the reabsorption and excretion of bicarbonate as the plasma concentration was elevated. Over the range of 26 to $55 \mathrm{mEq}$. per $\mathrm{L}$. in the plasma there was a curvilinear rise in bicarbonate reabsorption which reached a final average value of $3.8 \mathrm{mEq}$. per 100 $\mathrm{ml}$. of glomerular filtrate. The failure of previous workers to note such a curvilinear rise in bicarbonate reabsorption during acute respiratory acidosis (3) may have resulted from the fact that relatively few observations were made between plasma bicarbonate concentrations of 26 and $40 \mathrm{mEq}$. per L., a range over which the increasing rates of both reabsorption and excretion are most apparent.

In an attempt to find a simple mathematical function which might describe the curvilinear relationship between plasma bicarbonate concentration and the rate of bicarbonate reabsorption, the reciprocals of the values of the two variables were plotted one against the other. Figures 2 and 3 show the data from Tables I and II plotted in this fashion. The lines drawn through the points were calculated by the method of least squares. In each instance the $r$ value was 0.99 $(\mathrm{p}<0.01)$. In all 12 experiments the values for $r$ were found to lie between 0.97 and 0.99 $(\mathrm{p}<0.01)$.

From the linearity of the double reciprocal plot it follows that the relationship between plasma bicarbonate concentration and the rate of reabsorption takes the form $y=\frac{a x}{b+x}$, a rectangular hyperbola. ${ }^{1}$ There is no obvious explanation for this finding, but two considerations suggest a possible working hypothesis. First, previous observations on the effects of acetazolamide in metabolic acidosis suggest that carbonic anhydrase plays a critical role in the reabsorption of most, if not all, filtered bicarbonate (6). Second, the relationship between plasma concentration and rate of reabsorption in the present study takes the same form as the equation which describes the initial velocity of an enzymatic reaction as a function of substrate concentration $\left[v=\frac{V_{\max } S}{K m+S}\right.$ (Michaelis-Menten) $]$. As a tentative interpretation, it is therefore proposed that during acute respiratory acidosis carbonic anhydrase becomes rate-limiting in the overall process of bicarbonate reabsorption. It is recognized that data consistent with the kinetic theory, while providing presumptive evidence

1 This statement applies only at plasma concentrations above 23 to $25 \mathrm{mEq}$. per L. At plasma bicarbonate concentrations below this level, reabsorption of bicarbonate is known to be virtually complete and the relationship between the two variables is thus $y=x$. It would thus appear that there are two distinct components to the reabsorptive pattern observed between 0 and $55 \mathrm{mEq}$. per L. 
in its support, can in no way be taken as proof of the hypothesis.

In the present formulation the bicarbonate concentration of the initial glomerular filtrate has been used as the expression of substrate concentration. No assumptions were made concerning changes in bicarbonate concentration during the passage of filtrate along the renal tubule. However, the hypothesis carries the implication that either: 1) The bicarbonate concentration remains relatively constant over all but an insignificant segment of the renal tubule, or that 2) if major changes in concentration occur, they bear such a relationship to the initial concentration that this latter value may still be taken as equivalent to substrate in the MichaelisMenten equation. The apparent velocity constant $(\mathrm{Km})$ for this system is $6.0 \mathrm{mEq}$. per 100 ml. of filtrate (S.E. \pm 0.6 ) and the apparent $\mathrm{V}_{\max }$ is $8.4 \mathrm{mEq}$. per $100 \mathrm{ml}$. of filtrate (S.E. \pm 0.6 ).

It is noteworthy that the pattern of bicarbonate reabsorption in acute respiratory acidosis at plasma levels above $26 \mathrm{mEq}$. per L. is similar to the one found previously after the administration of acetazolamide to animals with metabolic acidosis (6). Acetazolamide is known to inhibit carbonic anhydrase in vitro, and it was suggested that the rate of reabsorption following injection of graded quantities of this drug was a function of residual enzyme activity in the renal tubular cells. The data from these studies, when tested by means of the double reciprocal plot, were also found to take the form of $y=\frac{a x}{b+x}$. Thus, as in the present study, the overall process of reabsorption appeared to follow the MichaelisMenten relationship. It was tentatively suggested that at plasma bicarbonate levels below the normal threshold, partial inhibition of carbonic anhydrase makes enzyme activity ratelimiting in the process of bicarbonate reabsorption (6).

The virtually complete reabsorption of bicarbonate in the absence of inhibitor suggests that the enzymatic reaction is not the rate-limiting step in the normal at subthreshold plasma levels (6). With a low concentration of bicarbonate in the filtrate it seems likely that the rate of filtration of bicarbonate is limiting and that

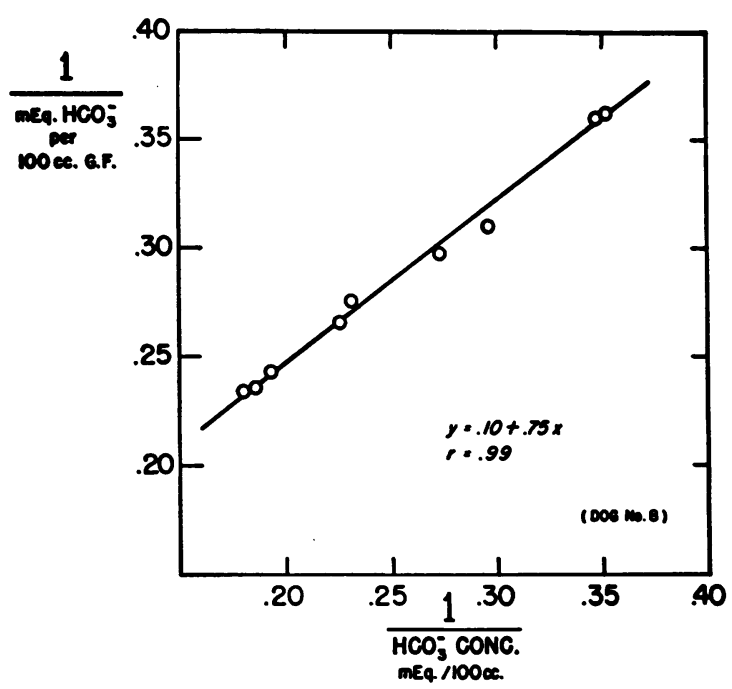

Fig. 3. Double Reciprocal Plot of Data FROM TABLE II

The line through the points was calculated by the method of least squares.

nearly complete removal of bicarbonate takes place before substrate comes into contact with the enzyme in the more distal tubular segments. As plasma bicarbonate rises, more enzyme would be expected to enter into the reaction as substantial quantities of bicarbonate reach additional segments. According to this view, enzyme is present in excess until a filtrate concentration of approximately $26 \mathrm{mEq}$. per L. is reached. At this point carbonic anhydrase all along the tubule is finally involved in the reabsorptive process and frank bicarbonate excretion begins. In the normal, regardless of further elevation of plasma bicarbonate concentration, the reabsorptive rate remains constant at approximately $2.4 \mathrm{mEq}$. per $100 \mathrm{ml}$. of glomerular filtrate. It is conceivable that a normal $\mathrm{pCO}_{2}$ imposes this limit by preventing full utilization of enzyme activity. In acute respiratory acidosis this limit is apparently removed and, according to the present hypothesis, the enzymatic step becomes rate-limiting in the reabsorptive process.

The following schema is suggested as a possible explanation for the experimental findings in terms of the present hypothesis. Extrusion of hydrogen ions from the cell releases hydroxyl ions which are neutralized by carbon dioxide under the catalytic activity of carbonic anhy- 
drase $\left(\mathrm{OH}^{-}+\mathrm{CO}_{2} \stackrel{\mathrm{CA}}{\rightleftharpoons} \mathrm{HCO}_{3}^{-}\right) .^{2}$ Carbon dioxide tension is assumed to influence hydrogen ion excretion independently of the enzymatic reaction. Thus, two rate-limiting steps can be visualized: 1) hydrogen ion secretion and 2) the enzymatic reaction which involves carbonic anhydrase. With normal $\mathrm{pCO}_{2}$, hydrogen ion secretion is fixed at a constant maximal rate. The concomitant hydroxyl ion production in the cell occurs at a rate so slow that carbonic anhydrase is not the rate-limiting factor in the reaction by which the hydroxyl ion is buffered with carbon dioxide. Such a fixed rate of hydrogen ion secretion would account for the constant maximum rate of bicarbonate reabsorption which is observed at plasma bicarbonate concentrations above $26 \mathrm{mEq}$. per L. In contrast it is postulated that elevation of $\mathrm{pCO}_{2}$ removes the limit on hydrogen ion secretion so that the latter increases as bicarbonate concentration in the filtrate is progressively elevated above $26 \mathrm{mEq}$. per $\mathrm{L}$. and as the $\mathrm{pH}$ of the filtrate risés. With concomitant increases in hydroxyl ion production, carbonic anhydrase becomes rate-limiting and the reaction follows the Michaelis-Menten relationship.

According to this schema, the hydroxyl ion is the limiting substrate in the reaction. However, since the data appear to follow the MichaelisMenten relationship when plasma bicarbonate concentration is plotted as substrate, it would follow as a corollary that intracellular hydroxyl ion concentration bears a direct relationship to the bicarbonate level in the filtrate.

The present data seem clearly to demonstrate that bicarbonate reabsorption rises in a curvilinear fashion as a function of plasma bicarbonate concentration but it is recognized that the theoretic formulation is highly tentative. It is hoped, however, that this framework may serve as a useful basis for further investigation.

\footnotetext{
2 This sequence of events, which has been suggested as the mechanism for gastric acid secretion (7) and for urinary acidification (8-10), assumes that secreted hydrogen ions are derived ultimately from water. Although the reaction is bimolecular, since carbon dioxide is always in excess relative to the hydroxyl ion, the kinetics are those of a monomolecular reaction.
}

\section{SUMMARY}

Studies of renal bicarbonate reabsorption in acute respiratory acidosis have demonstrated a curvilinear rise in reabsorption as plasma bicarbonate concentration was progressively elevated from 24 to $55 \mathrm{mEq}$. per L. The average final value for bicarbonate reabsorption was $3.8 \mathrm{mEq}$. per $100 \mathrm{ml}$. of glomerular filtrate. Frank excretion of bicarbonate began at a plasma level of approximately 26 to $30 \mathrm{mEq}$. per L. The relationship between plasma bicarbonate concentration and the rate of bicarbonate reabsorption has been found to have the form $y=\frac{a x}{b+x}$. As a tentative explanation for these findings it has been suggested that during acute respiratory acidosis an enzymatic reaction involving carbonic anhydrase is rate-limiting in the process of bicarbonate reabsorption.

\section{REFERENCES}

1. Relman, A. S., Etsten, B., and Schwartz, W. B. The regulation of renal bicarbonate reabsorption by plasma carbon dioxide tension. J. clin. Invest. 1953, 32, 972.

2. Brazeau, P., and Gilman, A. Effect of plasma $\mathrm{CO}_{2}$ tension on renal tubular reabsorption of bicarbonate. Amer. J. Physiol. 1953, 175, 33.

3. Dorman, P. J., Sullivan, W. J., and Pitts, R. F. The renal response to acute respiratory acidosis. J. clin. Invest. 1954, 33, 82.

4. Etsten, B., Reynold, R. N., and Li, T. H. Studies on ventilation and circulation during surgery using a volume displacement ventilator. Anesthesiology 1958, 19, 100.

5. Bonsnes, R. W., and Taussky, H. H. On the colorimetric determination of creatinine by the Jaffe reaction. J. biol. Chem. 1945, 158, 581.

6. Schwartz, W. B., Falbriard, A., and Relman, A. S. An analysis of bicarbonate reabsorption during partial inhibition of carbonic anhydrase. J. clin. In- . vest. 1958, 37, 744.

7. Davies, R. E. Hydrochloric acid production by isolated gastric mucosa. Biochem. J. 1948, 42, 609.

8. Orloff, J. The role of the kidney in the regulation of acid base-balance. Yale J. Biol. Med. 1956, 29, 211.

9. Berliner, R. W. Some aspects of ion exchange in electrolyte transport by the renal tubules in Metabolic Aspects of Transport Across Cell Membranes, Q. R. Murphy, Ed. Madison, The University of Wisconsin Press, 1957, p. 203.

10. Gilman, A. The mechanism of diuretic action of the carbonic anhydrase inhibitors. Ann. N. Y. Acad. Sci. 1958, 71, 355. 